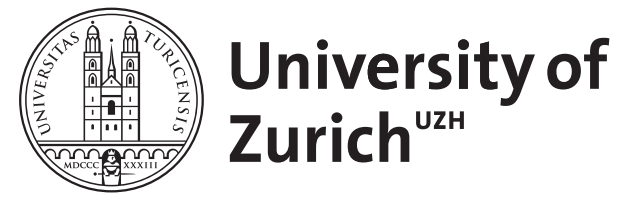
Archive

University of Zurich

University Library

Strickhofstrasse 39

CH-8057 Zurich

www.zora.uzh.ch

Year: 1993

\title{
Role of PrP in prion diseases
}

Weissmann, C ; Büeler, H ; Sailer, A ; Fischer, M ; Aguet, M ; Aguzzi, A

DOI: https://doi.org/10.1093/oxfordjournals.bmb.a072658

Posted at the Zurich Open Repository and Archive, University of Zurich

ZORA URL: https://doi.org/10.5167/uzh-155167

Journal Article

Published Version

Originally published at:

Weissmann, C; Büeler, H; Sailer, A; Fischer, M; Aguet, M; Aguzzi, A (1993). Role of PrP in prion diseases. British Medical Bulletin, 49(4):995-1011.

DOI: https://doi.org/10.1093/oxfordjournals.bmb.a072658 


\section{Role of PrP in prion diseases}

C Weissmann, H Büeler, A Sailer,

M Fischer, M Aguet,

Institut für Molekularbiologie I, Universität Zürich, Zürich, Switzerland

A Aguzzi

Institut für Neuropathologie, Universitätsspital, Zürich, Switzerland

Scrapie, the prototype of a group of diseases designated as transmissible spongiform encephalopathies (TSEs) or prion diseases, is a naturally occurring affliction of sheep which was recognized more than 250 years ago. Characteristically, affected animals present with twitching, excitability, intense itching and finally paralysis and death. Transmission of the disease by inoculation of healthy sheep and goats with lumbar cord of diseased animals was first demonstrated in $1936^{1}$ and soon confirmed by Gordon. ${ }^{2}$ This led to the recognition of the unusual properties of the pathogenic agent (later designated as 'prion' 3 , such as the extremely long incubation periods, exceeding 1 year, and resistance to high temperatures, formaldehyde treatment and UV irradiation.2,4,5

In a separate development, Creutzfeld-Jakob disease (CJD), Gerstmann-Sträussler-Scheinker disease (GSS) and kuru were characterized as slow degenerative diseases of the central nervous system. The suggestion by Hadlow ${ }^{6}$ that these diseases might be the counterpart of scrapie in humans was followed by long-term inoculation studies by Gajdusek and his colleagues which resulted in the transmission, first of $\mathrm{kuru}^{7}$, then of $\mathrm{CJD}^{8}$ to chimpanzees. Later, GSS was also transmitted to the chimpanzee 9 and to the mouse. ${ }^{10}$ Recently we have witnessed the emergence of a new form of a prion disease, namely bovine spongiform encephalopathy (BSE), which is attributed to the feeding of cattle with meat and bone meal supplements derived from scrapie-contaminated sheep and then cattle offal. 11,12

The overall properties of the prion differ from those of any known virus or viroid ${ }^{2-4,13}$ and early on gave rise to speculations that it might be devoid of both nucleic acid and protein, 14 consist of protein only ${ }^{15-17}$ or be a polysaccharide 17 a or a membrane fragment. ${ }^{18}$ In this article we review the current hypotheses regarding the pathogenesis of

Note added in proof: Unheated brain extracts of PrP0/0 mice 25,33 and 48 weeks after inoculation with scrapie prions show no scrapie infectivity. Thus, the positive result for the 20-week PrP0/0 mouse (Table) is likely accidental. 
this class of diseases (for recent reviews, see Refs 19-24), in particular the so-called 'protein only' hypothesis and the major lines of evidence in its support, and describe experiments carried out in our laboratory demonstrating the essential role of the host gene Prn-p in the pathogenesis of scrapie. 25

\section{THE 'PROTEIN ONLY' HYPOTHESIS}

Prusiner has suggested that the prion is devoid of nucleic acid and identical with PrPSc, a modified form of PrPC (the 'protein only' hypothesis). ${ }^{26} \mathrm{PrPC}$ is a normal host protein $27-29$ encoded within a single exon of a single copy gene ${ }^{30}$ and is found predominantly on the outer surface of neurons, attached by a glycosyl phosphatidyl inositol anchor $19,26,31,32$ but also in a variety of other tissues, both in the embryonic and the adult mouse. 33,34

PrPSc is defined as a largely protease-resistant form of PrPC which readily forms aggregates after treatment with detergents and protease.27, 35-37 It accumulates intracellularly, in cytoplasmic vesicles ${ }^{38,39}$ and is the major component of the extracellular amyloid plaques characteristic for some forms of prion diseases. No chemical differences have so far been detected between PrPSc and PrPC19,40,41, however, it must be stressed that the ratio of infectious units to PrPSc molecules is in the order of $1: 100000,42$ so that if the infectious entity were a subspecies of $\mathrm{PrPSc}$ or a different modification of PrP altogether a chemical difference between $\mathrm{PrPC}$ and the infectious subspecies could be analytically undetectable.

Prusiner proposed that $\mathrm{PrPSc}$, when introduced into a normal cell, causes the conversion of $\operatorname{Prp}^{C}$ or its precursor into PrPSc19,27,43,45-46 (Fig. 1A). The nature of the conversion is unknown and could be due to a chemical or conformational modification, during or after its synthesis. However, the existence of many different strains of scrapie which can be propagated in one and the same inbred mouse line, and the apparent mutability of the agent ${ }^{21-23}$ are cited in support of the virino hypothesis (Fig. 1B), which holds that the infectious agent consists of a nucleic acid genome and the host-derived PrP, which is recruited as some sort of coat. 27,48 No credible evidence for such a nucleic acid has yet been forthcoming.22,43,44,48 Finally, the possibility that the infectious agent is a virus with unusual properties is still upheld by some. 24,49 


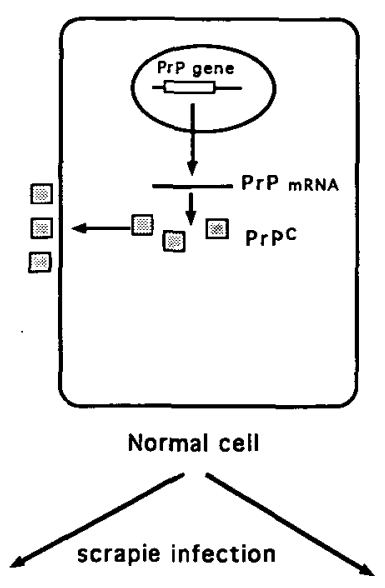

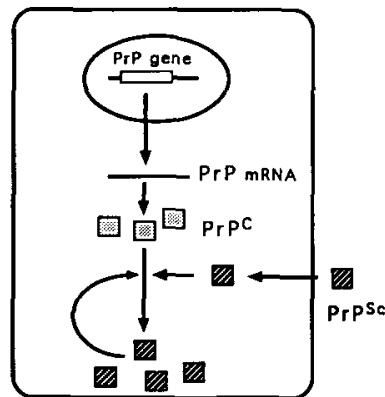

A. "protein oniy" model

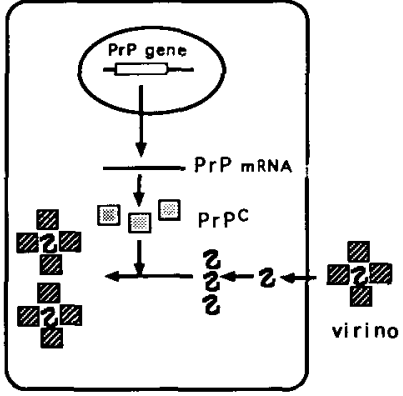

B. virino model

PrPSc

$\mathbf{Z}=$ scrapie-specific nucleic acid

Fig. 1 Models for the propagation of the scrapie agent (prion). (A) The 'protein only' model assumes that the prion is identical with PrPSc. Exogenous PrPSc causes the conversion of the normal cellular protein PrPC into PrPSc. (B) The 'virino hypothesis' assumes that the infectious agent consists of a scrapie-specific nucleic acid associated with or packaged in PrPSc. The 'scrapie specific nucleic acid' (to date never found) is replicated in the cell and recruits $\operatorname{Pr}_{\mathrm{PC}}$ into association with it. Strain specificity would be mediated by the nucleic acid.

\section{PREVIOUS EVIDENCE BEARING ON THE RELATIONSHIP OF PrP TO TRANSMISSIBLE SPONGIFORM ENCEPHALOPATHIES}

\section{Scrapie infectivity is associated with PrPSc}

Purification of scrapie infectivity results in a preparation highly enriched with regard to $\operatorname{PrPSc} 35,50,51$ Conversely, purification of PrPSc by affinity chromatography on an anti-PrP antibody column leads to enrichment of infectivity. 52 


\section{A nucleic acid larger than about 100 nucleotides is not essential for infectivity of scrapie prion preparations}

This claim is based on: (a) the unusually small target size of scrapie infectivity for UV and ionizing radiation $16,53,54$; (b) the low ratio of nucleic acids to infectious units in highly purified prion preparations ${ }^{44}$ and the failure to find scrapie-specific nucleic acid in prion preparations or scrapie-infected brain tissue $22,43,55$; (c) resistance of infectivity to treatment with agents modifying or damaging nucleic acids. ${ }^{3}$ Collectively, these data suggest that a nucleic acid of more than 50-100 nucleotides is not required for infectivity (but see Ref. 56 for a different conclusion).

\section{The susceptibility of a host to scrapie infection is co-determined by the prion inoculum and the PrP gene}

The significance of the host PrP genotype for the susceptibility to scrapie infection and the course of the disease is revealed by two sets of findings. First, the incubation time for one and the same prion isolate may be different in distinct mouse strains, and is determined predominantly by $\operatorname{Sin} c^{57,58}$ or $P r n$-i 59,60 which is very closely linked to or coincident with Prn-p, the gene encoding PrP.59-63 Second, when prions are transmitted from one animal species to another, disease often develops only after a very long incubation period, if at all. However, upon serial passaging in the new species, the incubation time may decrease dramatically and then stabilize. At least in the case of hamster and mouse, this so-called species barrier ${ }^{64}$ can be overcome by introducing into the recipient host the PrP transgene from the prion donor. ${ }^{45,65}$ Moreover, prion preparations from mice carrying hamster PrP-transgenes and inoculated with hamster scrapie prions are highly infectious to the hamster but not to the mouse. The same transgenic mouse strain, infected with mouse-derived prions, yields preparations highly infectious for mice but not for hamsters. ${ }^{45}$ Within the framework of the 'protein only' hypothesis this means that hamster PrPC, but not murine $\mathrm{PrPC}$, is a suitable substrate for conversion to hamster $\mathrm{PrPSc}^{\mathrm{Ps}}$ by hamster prions and vice versa.

\section{Hereditary forms of spongiform encephalopathies are linked to mutations of the PrP gene}

The human prion diseases, Creutzfeldt-Jakob (CJD) and GerstmannSträussler-Scheinker disease (GSS), are very rare in the overall population, but also occur as a familial form. $8,9,66,67$ Hsiao et al68 found that in two apparently unrelated GSS families the disease is tightly linked to a proline-to-leucine change in codon 102 of one of the Prn-p alleles. Subsequently other GSS and CJD families were identified, carrying the 
102 mutation or one of a number of other mutations in the PrP gene (for a review see Ref. 69). Prusiner ${ }^{26}$ proposed that the mutations allow spontaneous conversion of $\mathrm{PrPC}$ into $\mathrm{PrPSc}$ with a frequency sufficient to allow the disease to be expressed within the lifetime of the individual. Sporadic CJD would be attributable to a somatic mutation in the Prn-p gene or to rare instances of spontaneous conversion of $\mathrm{PrPC}$ into PrPSc (Fig. 2A).

Hsiao et al. ${ }^{70}$ showed that mice carrying a murine PrP transgene with the pro $\rightarrow$ leu mutation corresponding to the human GSS mutation at position 102 spontaneously come down with a lethal scrapie-like disease. However, it has not yet been reported whether or not the brains of these animals contain prions.

\section{SUSCEPTIBILITY TO SCRAPIE OF MICE DEVOID OF PrPC}

The 'protein only' hypothesis predicts that in the absence of $\operatorname{PrPC}$, mice should be resistant to scrapie infection, both with regard to symptoms and to propagation of the infectious agent.

\section{Generation and properties of Prn-p $p^{0 / 0}$ mice}

Mice devoid of $\mathrm{PrP}^{71}$ were generated by the general approach described by others. ${ }^{72-75}$ In short, one Prn-p allele of murine embryonic stem (ES) cells was disrupted (Fig. 2A) by homologous recombination with a $4.8 \mathrm{~kb}$ DNA fragment in which codons 4-187 of the 254-codon open reading frame, which is located within a single exon, were replaced by a neomycin phosphotransferase (neo) gene under the control of the HSV TK promoter (Fig. 2B). In the resulting construction (Fig. 2C) the first 3 Prn-p codons, the neo encoding sequence and the residual $67 \mathrm{Prn}-\mathrm{p}$ codons were fused in frame, with one nonsense codon interposed between the initial Prn-p codons and the neo sequence and two nonsense codons between the latter and the residual Prn-p sequence (Fig. 2D). Thus, the synthesis of PrP or any fragment thereof is precluded. Blastocysts from black mice were injected with agouti ES cells carrying the disrupted Prn-p gene and implanted into foster mothers. Chimeric males (showing agouti patches) were mated with wild type black mice and agouti offspring carrying the disrupted gene were identified by PCR analysis. Prn-po/+ heterozygotes were mated and 176 superficially indistinguishable offspring analyzed by PCR. Of these, 24\% were homozygous for the disrupted Prn-p gene.

As shown by Northern analysis, normal PrP mRNA was not detectable in brain from Prn-p ${ }^{0 / 0}$ homozygotes, however substantial quantities of a fused mRNA containing the neo and the residual Prn-p sequence were present. Western analysis of brain proteins showed that 
A

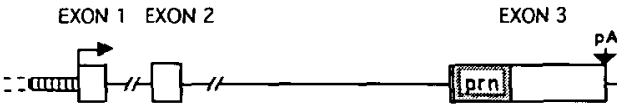

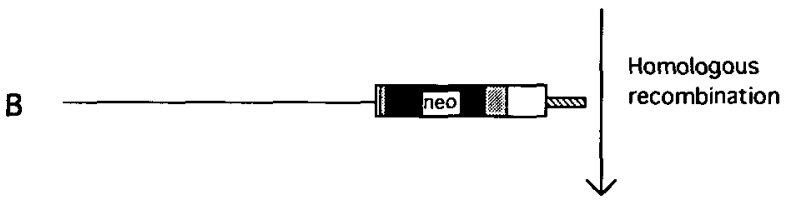
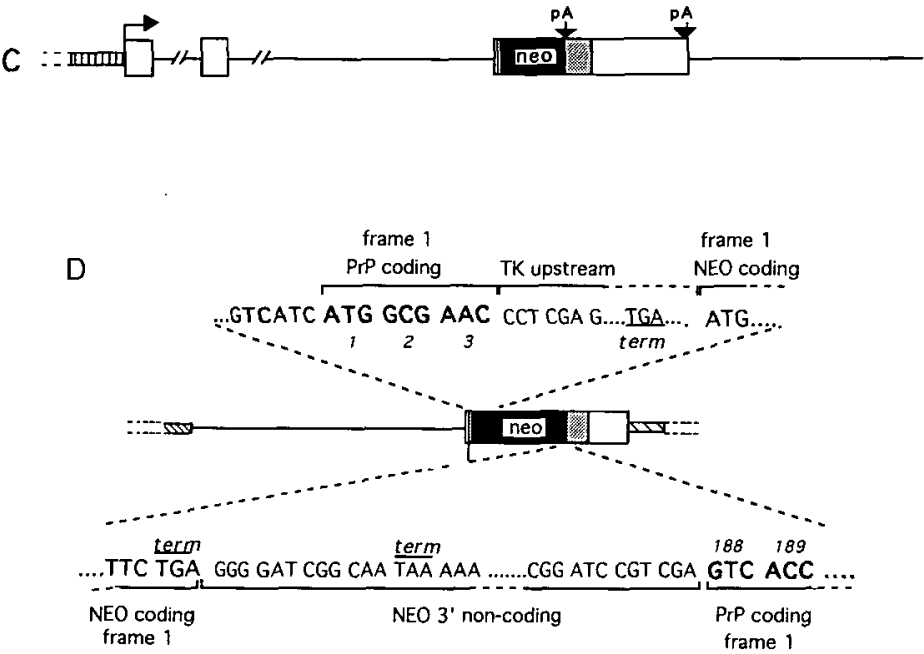

Fig. 2 Construction of the PrP targeting vector. (A) Map of the murine PrP gene. ${ }^{88}$ (B) The targeting vector was constructed by replacing 552 bp of the $P m-p$ coding region (extending from position 10-562) by a $1.1 \mathrm{~kb}$ cassette containing the HSV thymidine kinase promoter followed by the neo gene. (C) The disrupted PrP gene. (D) The first 3 Prn-p codons, the neo coding sequence and the residual $67 \mathrm{Prn}-\mathrm{p}$ codons were fused in frame, with one nonsense codon interposed between the initial Prn-p codons and the neo sequence and two nonsense codons between the latter and the residual Prn-p sequence.

PrP was undetectable in $P r n-p^{0 / 0}$ samples and present at about half the normal level in Prn-po/+ samples.

No gross abnormalities were noted in Prn-p $0 / 0$ mice at the macroscopic or microscopic level, in particular of the brain, skeletal muscle and visceral organs. ${ }^{71,76}$ Disruption of the Prn-p gene had no detectable effect on the normal maturation of the lymphocyte subsets. No significant difference in the response of splenocytes from $P m-p^{O / O}$ and $P r n-p^{+/+}$mice to activation by concanavalin A was detected. ${ }^{71}$ 
Because $\operatorname{PrPC}$ is a predominantly neuronal protein and present in a high proportion of hippocampal neurons, the learning ability of $\mathrm{Prn}$ $p^{0 / 0}, P r n-p^{+/+}$and $P r n-p^{0 /+}$ mice, all derived from the mating of the first generation of heterozygotes, was compared. Three tests, the swimming navigation test, 77 the $Y$-maze discrimination test ${ }^{78}$ and the two-way avoidance (shuttlebox) test ${ }^{79}$ revealed no differences between the three groups of mice.

Homozygous Prn-p $0 / 0$ mice are fertile and normal progeny result from homozygous Prn-p $p^{0 / 0}$ breeding pairs. No abnormalities of homozygotes were recorded during 18 months of observation. It is surprising that a protein expressed in many areas of the brain and in other tissues and whose gene has been found in mammals, birds and fish can be ablated without apparent detrimental effects. It is possible that its function is too subtle to be detected under laboratory conditions, or that it can be replaced by some other gene product(s), particularly if adaptive processes are facilitated during development.

\section{Challenge of Prn-p $\mathbf{p}^{0 / 0}$ and Prn-p $\mathbf{p}^{0 /+}$ mice with scrapie prions}

Mice devoid of PrP were challenged with mouse prions and proved to be completely protected against scrapie disease, at least up to 14 months after inoculation (Fig. 3). Moreover, even heterozygous $\mathrm{Prn}-\mathrm{p}^{0 /+}$ mice proved to be partially protected, inasmuch as scrapie-inoculated animals showed signs of scrapie only 253-337 days after inoculation but are still alive after 380 days, while all $P r n-p^{+/+}$controls died within about 180 days. Moreover, disease progression in $\mathrm{Prn-} \mathrm{p}^{0 /+}$ mice is distinctly slower than in Prn- $p^{+/+}$mice, the interval between first symptoms and death being 13 days in the case of Prn-p ${ }^{+/+}$mice while no Prn- $p^{0 /+}$ mice have died to date, about 3 months after the appearance of scrapie symptoms (Büeler and Weissmann, unpublished results).

We conclude that development of scrapie symptoms and pathology is strictly dependent on the presence of $\operatorname{PrP}$ and that incubation time and disease progression are inversely related to the level of PrP. It has previously been found that the length of the scrapie incubation time for hamster-derived prions in mice expressing SHaPrP genes was inversely related to the level of SHaPrP. 45

\section{Are prions propagated in Prn-p ${ }^{0 / 0}$ mice?}

It was shown that if infectious agent is propagated in Prn-p $p^{0 / 0}$ mice, this would be at a level about five orders of magnitude lower than that in $P r n-p^{+/+}$animals. ${ }^{25}$ Scrapie prion titers were determined by preparing tissue extracts at various times after inoculation, heating them for $20 \mathrm{~min}$ at $80^{\circ} \mathrm{C}$ to destroy any adventitious conventional pathogens and inoculating them into wild type indicator mice. In scrapie- 

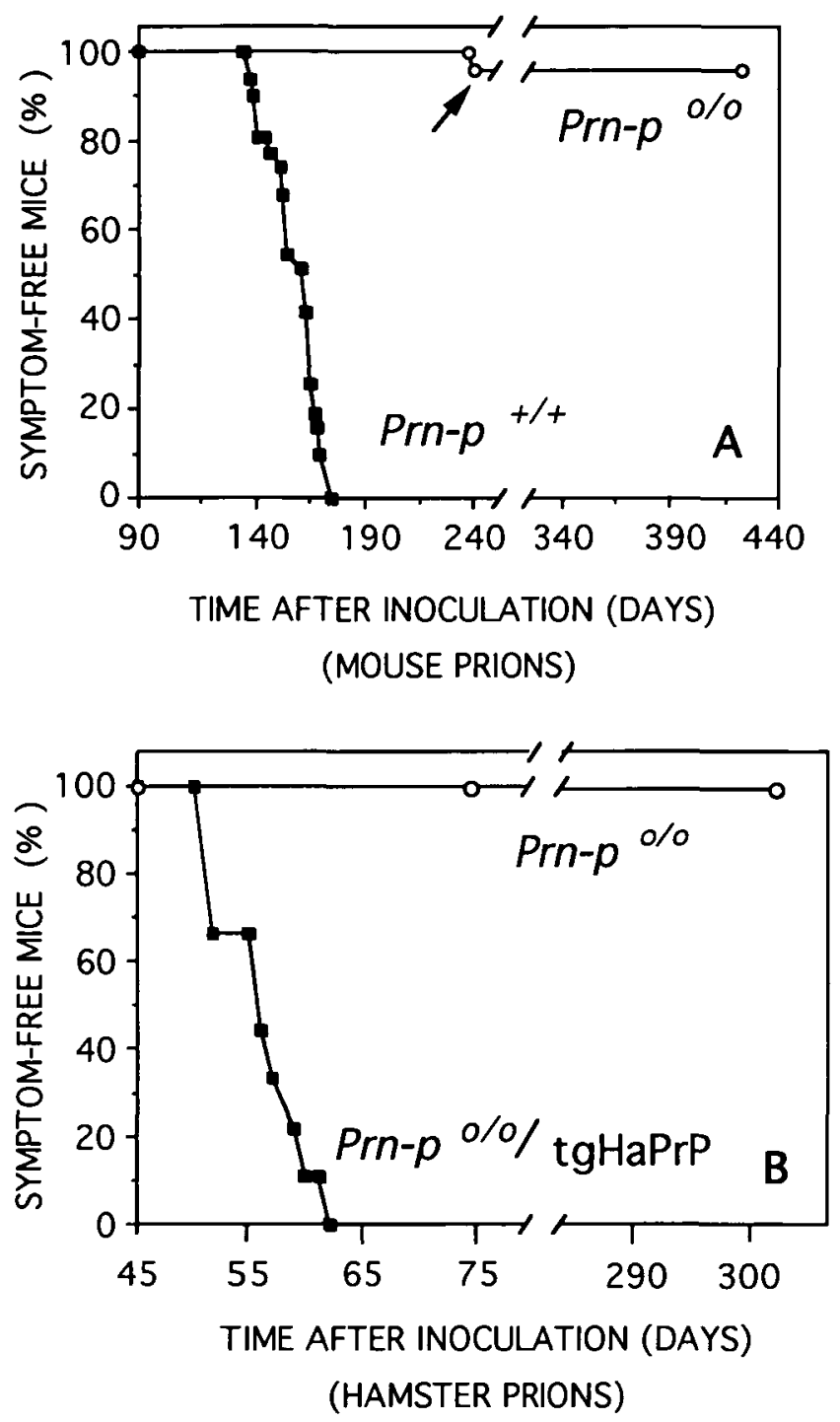

Fig. 3 Susceptibility of mice with various PrP genotypes to inoculation with scrapie prions. Mice were inoculated intracerebrally and the percentage of mice remaining free of scrapie symptoms was plotted as a function of time. (A) Prn-p $0 / 0$ and $P r n-p^{+/+}$mice were inoculated with mouse prions. One Prn-p $0 / 0$ mouse (arrow) showed ataxic gait and was sacrificed at 240 days: it showed no histopathological changes typical for scrapie and brain homogenate from this mouse did not transmit scrapie to CD-1 indicator mice after more than 170 days. (B) $P r n-p^{0 / O}$ and $P r n-p^{\alpha /} / \mathrm{tgHaPrP}$ mice (Prn-po/O mice carrying Syrian hamster transgenes) were inoculated with hamster scrapie prions. 
at 8 weeks and increased to about $8.6 \log L_{50}$ units/ml by 20 weeks after inoculation (Table). No infectious agent was detected in Prn-p $\mathbf{p}^{0 / 0}$ animals 25 weeks after inoculation, the latest time point for which data are presently available. However, in a parallel assay using unheated samples, a low level of infectivity, about $3.2 \log L D_{50}$ units $/ \mathrm{ml}$, was found in the 20 week sample from Prn-p $p^{0 / 0}$ animals. Because only one $P r n-p^{0 / 0}$ brain sample in the entire experiment was positive, accidental contamination of the homogenate or infectivity due to residual traces of inoculum in the occasional mouse cannot be excluded. However, the possibility must be considered that the infectious agent is something other than PrPSc, and that in the absence of PrPSc in the host it is much less infectious than in its presence. This question can only be resolved by further experiments, which are now underway.

Table Prion titers in brain and spleen of $P r m-P^{+/+}$and $P r n-p^{O / O}$ micea

\begin{tabular}{|c|c|c|c|c|c|c|}
\hline \multirow{2}{*}{$\begin{array}{l}\text { Time after } \\
\text { inoculation }\end{array}$} & \multicolumn{2}{|c|}{ Brain (heated) } & \multicolumn{2}{|c|}{ Brain (not heated) } & \multicolumn{2}{|c|}{ Spleen (heated) } \\
\hline & $\mathrm{PrP}^{+/+}$ & $\operatorname{PrP} 0 / 0$ & $\mathrm{PrP}+/+$ & $\operatorname{PrP} 0 / 0$ & $\mathrm{PrP}+/+$ & $\operatorname{PrP} 0 / 0$ \\
\hline 4 days & $<1.5$ & $2.0^{\mathrm{b}}$ & n.d. & n.d. & $5.7 \pm 0.9$ & $2.3^{c}$ \\
\hline 2 weeks & $<1.5$ & $<1.5$ & n.d. & n.d. & $6.2 \pm 0.8$ & $<1.5$ \\
\hline 8 weeks & 5.4 & $<1.5$ & $7.7 \pm 0.6$ & $<1.5$ & $6.9 \pm 1.0$ & $<1.5$ \\
\hline 12 weeks & 6.8 & $<1.5$ & $7.1 \pm 1.6$ & $<1.5$ & $5.9 \pm 0.6$ & $<1.5$ \\
\hline 20 weeks & 8.6 & $<1.5$ & $7.7 \pm 1.1$ & $3.2 \pm 1.4^{d}$ & $6.9 \pm 0.6$ & $<1.5$ \\
\hline $23 / 25$ weeks & $8.1 \pm 0.8$ & $<1.5$ & n.d. & n.d. & n.d. & $<1.5$ \\
\hline
\end{tabular}

aThe samples designated 'heated' were kept $20 \mathrm{~min}$ at $80^{\circ} \mathrm{C}$ prior to inoculation. The titers of brain homogenates recovered at 8,12 and 20 weeks after inoculation and of the Chandler-derived mouse prion inoculum 'RML' $\left(8.5 \log \mathrm{LD}_{50}\right.$ units/ml) were determined by end point dilution. The titers of the other samples were determined by the incubation time assay (Ref. 25) b1/6 mice died after inoculation with $10^{-1}$ diluted homogenate. ${ }^{2} / 6$ mice died after inoculation with $10^{-1}$ diluted homogenate $\mathrm{d} 6 / 6$ mice died after inoculation with $10^{-1}$ diluted homogenate

\section{Restoration of susceptibility to scrapie by introduction of $\operatorname{PrP}$ transgenes.}

When ablation of a gene product gives rise to a specific phenotype, in this case resistance to scrapie, it is desirable to demonstrate that reinstatement of the gene restores the original phenotype. Indeed, insertion of mouse PrP genes rendered Prn-p/o mice susceptible to mouse prions (Fischer and Weissmann, unpublished data). More interestingly, introduction of hamster PrP transgenes into $\mathrm{Prn}-\mathrm{p}^{0 / 0}$ mice rendered them very susceptible to hamster-derived prions ( $56 \pm 3$ days incubation time) but much less so ( $303 \pm 19$ days) to mouse-derived prions, demonstrating the requirement of a homotypic relationship between incoming 
prion and resident PrP protein for prion propagation and development of pathology, as foreshadowed by the results of Prusiner et al. 45

\section{IMPLICATIONS AND OUTLOOK}

Both the biochemical and genetic data discussed in this review support the proposal that the prion is composed partly or entirely of a $\operatorname{PrP}$ isoform (either PrPSc or a subfraction of it), and that protein-encoding nucleic acid is not an essential component. Other explanations of the data, such as that $\mathrm{PrPC}$ is or contributes to a receptor for the scrapie agent, while less likely, are not yet formally excluded.

\section{How is PrPC converted to PrPSe?}

No chemical differences between $\mathrm{PrPC}$ and PrPSc have been detected, however, as pointed out above, the ratio of infectious units to PrPSc molecules is about 1:105. Therefore, chemical analyses may not bear on the structure of a conjectural minor component responsible for the infectivity. Nonetheless, this minor component is likely PrPC-derived, as indicated by the genetic evidence, and is as resistant to proteinase digestion as PrPSc.80

Prusiner postulated that the difference between $\operatorname{Prp}^{\mathrm{C}}$ and $\operatorname{Prp} \mathrm{Sc}$ is conformational. In Figure 4A it is suggested that a molecule of PrPSc binds to $\mathrm{PrPC}$ and thereby imposes its conformation upon it. The species barrier is explained by the assumption that heterologous $\operatorname{PrP}$ species interact poorly and/or that the conversion only occurs rarely. Mutations of the Gerstmann-Sträussler and CJD type would allow spontaneous, albeit very rare conversion events, yielding $\operatorname{PrPSc}$ that can then act catalytically (Fig. 4B). Sporadic cases of CJD could be attributed to even rarer cases of spontaneous conversion of wild type $\mathrm{PrPC}$ or of a somatically mutated $\mathrm{PrPC}$.

It has so far not been possible to denature infectious preparations containing $\operatorname{Prp} S \mathrm{sc}$ and renature them to regain infectivity and/or protease resistance ${ }^{81}$ contrary to previous reports, 82,83 nor has it been possible to convert $\operatorname{PrPC}$ into PrPSc in a cell free system. ${ }^{84}$ In addition, $\operatorname{Prp} C$ does not, or only in the rarest of cases, spontaneously convert to PrPSc in vivo, despite the inordinate stability of PrPSc. To explain these findings within the framework of the 'protein only' model, Figure $4 \mathrm{C}$ suggests that the PrPSc state is separated from that of PrPC and of a random coil by very high activation energy barriers, while the PrP state is separated from the random coil state by a far lower barrier. Thus, the only way PrPC can convert to PrPSc is by 'tunnelling' through the activation energy barrier by a catalyzed, probably energy-dependent process which might involve chaperonins. 


\section{THE "PROTEIN ONLY" HYPOTHESIS"}
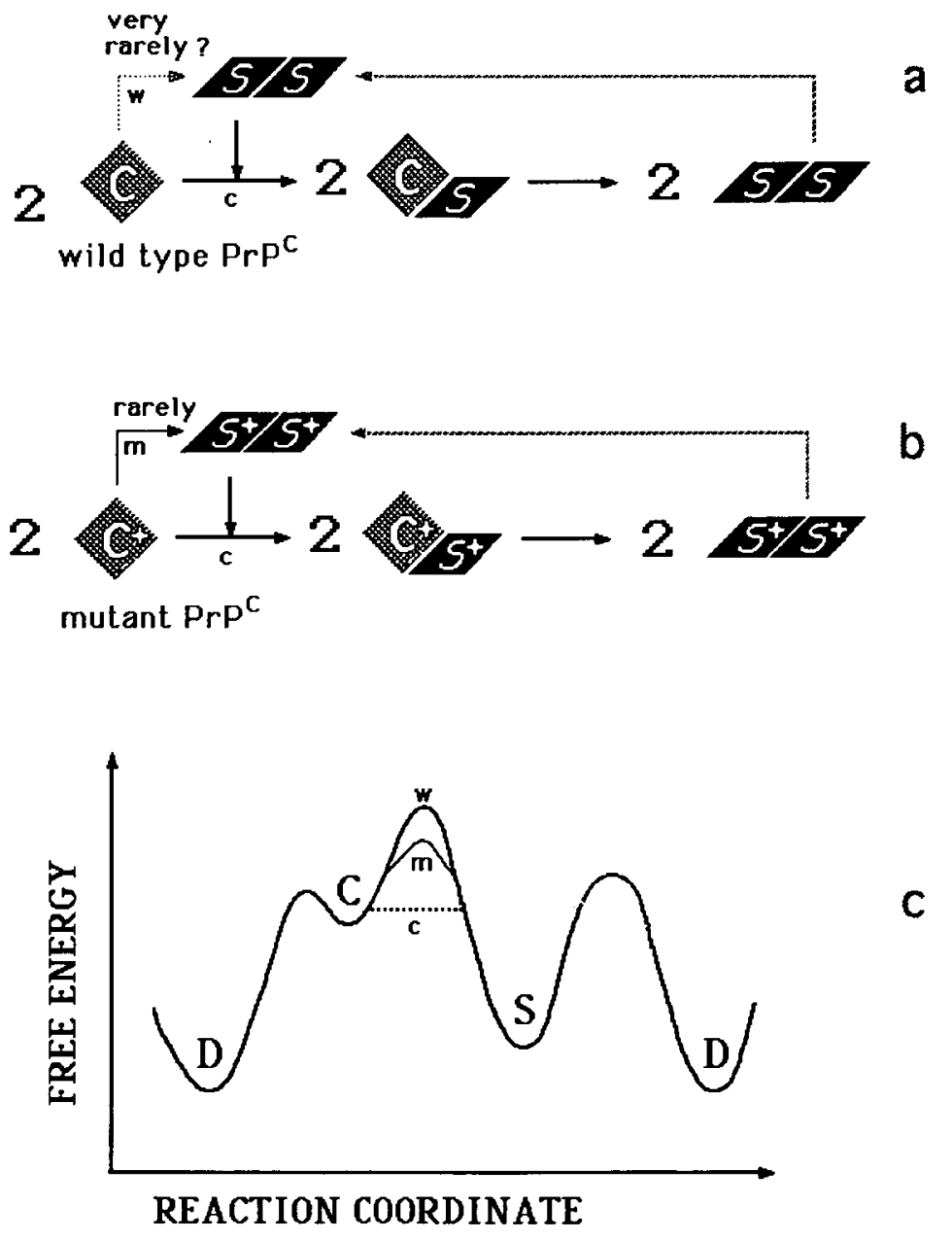
Fig. 4 Model for the catalyzed conformational conversion of $\operatorname{PrPC}$ to an infectious PrP form. (A) Following a proposal by Prusiner ${ }^{45} \mathrm{PrPC}_{(\mathrm{C})}$ is converted to the conformer PrPSc (S) via dimers formed with exogenously introduced PrPSc. This results in an exponential cascade of conversion. Sporadic forms of prion disease (such as sporadic CJD) may come about when an extremely rare event $(w)$ leads to spontaneous conversion of $\mathrm{PrPC}$ to $\mathrm{PrPSc}$ and gives rise to a conversion cascade. (B) In the case of certain mutations in $\operatorname{PrPC}(\mathrm{C}+)$ spontaneous conversion $(\mathrm{m})$ to $\mathrm{PrPSc}$ may occur about a million times more frequently than in the case of the wild type protein, but still remains a rare event, explaining why familial forms of prion diseases arise only late in life. (C) Postulated energy diagram for different forms of PrP. The PrPC conformation (C) is separated from the PrPSc conformation (S) by a high activation energy barrier, and from the denatured state (D) by a low activation energy barrier. Thus a spontaneous conformational change from PrPC to PrPSc (pathway w) will be extremely rare. Interaction of $\mathrm{PrPC}$ with PrPSc facilitates the conversion (pathway c) by lowering the activation energy for the transition. In the case of certain mutations in PrPC the activation energy for the conversion (pathway $m$ ) is lowered, increasing the probability of the spontaneous conformational change to PrPSc.

\section{Scrapie strains}

As mentioned above, the finding that there are many distinct strains of scrapie prions which can be propagated in one and the same mouse strain (homozygous with regard to its PrP gene) is not readily explained by the 'protein only' hypothesis (for a review, see Ref 23 ) because it implies that an incoming PrPSc strain can convert one and the same PrP precursor into a likeness of itself, and that this can happen for several if not many different strains. Two subsidiary hypotheses have been suggested to circumvent this difficulty. The 'unified theory' 85 proposes that PrPSc is associated with a small host-derived nucleic acid which is not required for infectivity but determines the characteristic phenotype of the strain. This nucleic acid would be replicated by host cell enzymes and then associate with newly formed PrPSc leading to preservation of the prion's phenotype. The 'targeting theory' 86 (and KH Meyer, personal communication 1991) proposes that PrPSc carries a variable modification, for example carbohydrate residues, which target it to a specific subset of cells. These cells would impart the same modification to the newly formed PrPSc molecules. Different strains would thus be targeted to different subsets of cells and retain their specific modification (Fig. 5). This hypothesis is supported by the observation that different hamster prion strains ${ }^{86}$ or mouse prion strains ${ }^{87}$ give rise to different patterns of PrPSc deposition in the brain. It predicts that if two different prion strains are propagated through a singular cellular species they should emerge with identical properties.

\section{PRACTICAL IMPLICATIONS OF PRION RESEARCH}

The results of Büeler et al 25,71 show that it is possible to generate normal mice which are resistant to scrapie by knocking out their PrP genes. 

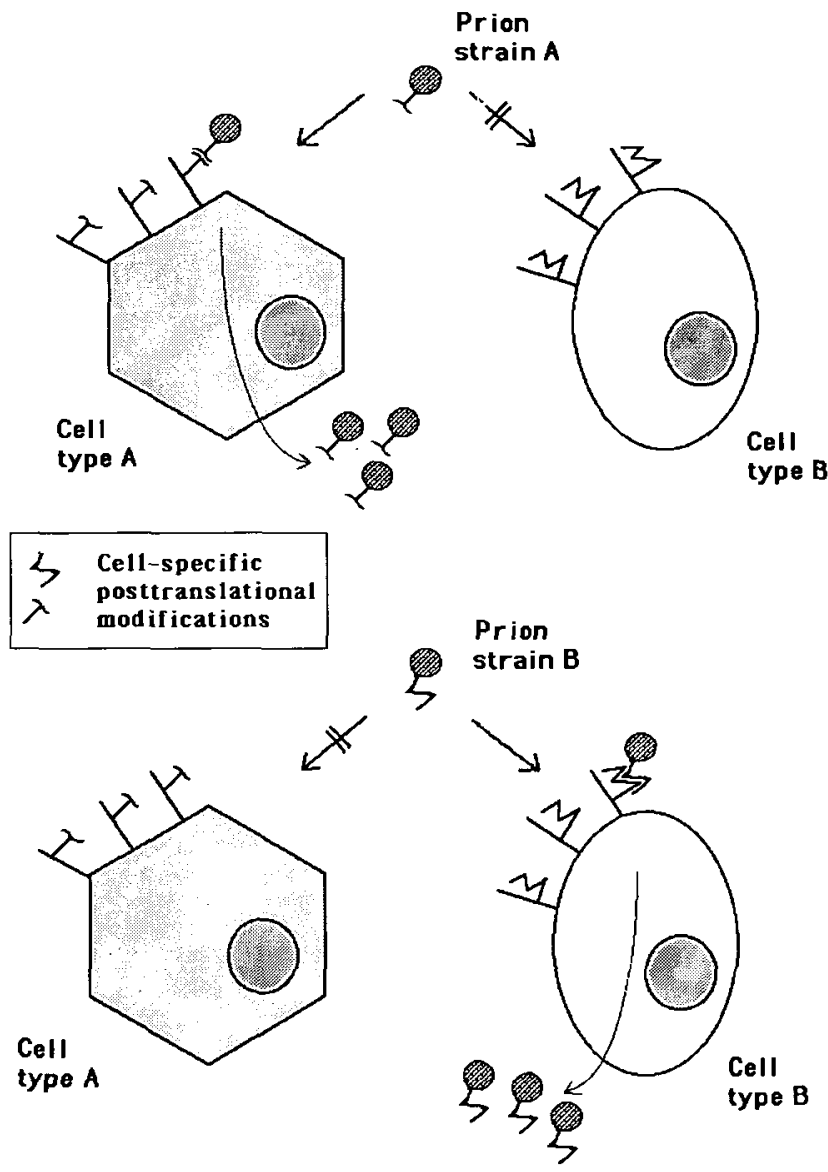

Fig. 5 The 'targeting model' to explain prion strain specificity. It is assumed that strain specificity of the prion is imparted by a cell specific post-translational modification which targets the prion to the same type of cell as the one in which it was synthesized. A possible modification would be glycosylation.

In principle it should thus be possible to breed sheep or cattle resistant to this disease, either by PrP gene disruption or by the introduction of transgenes expressing PrP antisense RNA. Moreover, the fact that Prn-p ${ }^{0 /+}$ heterozygous mice show much longer scrapie incubation times than their wild type counterparts argues that disease progression may be rate-limited by the $\mathrm{PrPC}$ concentration. This conclusion is consistent with the observation that in several mouse lines containing hamster PrP transgenes the incubation time for hamster prion-induced scrapie is a function of the hamster PrP expression level. ${ }^{45} \mathrm{~A}$ practical implication of this conclusion is that a moderate reduction of PrPC synthesis, such 
as might eventually be achieved by antisense oligonucleotide therapy, could substantially mitigate disease progression in incipient cases of spongiform encephalopathies.

\section{ACKNOWLEDGEMENTS}

This work was supported by the Erziehungsdirektion of the Kanton of Zürich and grants of the Schweizerische Nationalfonds to CW. We thank Dr S Prusiner for advice and discussions.

\section{REFERENCES}

1 Cuille J, Chelle PL. Experimental transmission of trembling to the goat. C R Seances Acad Sci 1939; 208: 1058-1160.

2 Gordon WS. Vet Rec 1946; 58: 516.

3 Prusiner SB. Novel proteinaceous infectious particles cause scrapie. Science 1982; 216: 136-144.

4 Pattison IH. Resistance of the scrapie agent to formalin. J Comp Pathol 1965; 75: 159-164.

5 Alper T, Haig DA, Clarke MC. The exceptionally small size of the scrapie agent. Biochem Biophys Res Commun 1966; 22: 278-284.

6 Hadlow WJ. Scrapie and kuru. Lancet 1959; 2: 289-290.

7 Gajdusek DC, Gibbs CJ Jr, Alpers M. Experimental transmission of a Kuru-like syndrome to chimpanzees. Nature 1966; 209: 794-796.

8 Gibbs CJ Jr, Gajdusek DC, Asher DM et al. Creutzfeldt-Jakob disease (spongiform encephalopathy); Transmission to the chimpanzee. Science 1968; 161: 388-389.

9 Masters CL, Gajdusek DC, Gibbs CJ Jr. Creutzfeldt-Jakob disease virus isolations from the Gerstmann-Sträussler syndrome. Brain 1981; 104: 559-588.

10 Tateishi J, Ohta M, Koga M, Sato Y. Transmission of chronic spongiform encephalopathy with kuru plaques from humans to small rodents. Ann Neurol 1979; 5: 581-584.

11 Wells GAH, Scott AC, Johnson CT et al. A novel progressive spongiform encephalopathy in cattle. Vet Rec 1993; 121: 419-420.

12 Wilesmith JW, Ryan JB, Hueston WD, Hoinville LJ. Bovine spongiform encephalopathy: epidemiological features 1985 to 1990 . Vet Rec 1992; 130: 90-94.

13 Brown P, Liberski PP, Wolff A, Gajdusek DC. Resistance of scrapie infectivity to steam autoclaving after formaldehyde fixation and limited survival after ashing at 360 degrees C: practical and theoretical implications. J Infect Dis 1990; 161: 467-472.

14 Stamp JT, Brotherston JG, Zlotnik I, Mackay JM, Smith W. Further studies on scrapie. J Comp Pathol 1959; 69: 268-280.

15 Griffith JS. Self-replication and scrapie. Nature 1967; 215: 1043-1044.

16 Alper T, Cramp WA, Haig DA, Clarke MC. Does the agent of scrapie replicate without nucleic acid? Nature 1967; 214: 764-766.

17 Pattison IH, Jones KM. The possible nature of the transmissible agent of scrapie. Vet Rec 1967; 80: 2-9.

18 Gibbons RA, Hunter GD. Nature of scrapie agent. Nature 1967; 215: 1041-1043.

19 Prusiner SB. Molecular biology of prion diseases. Science 1991; 252: 1515-1522.

20 Weissmann C. Spongiform encephalopathies. The prion's progress (news). Nature 1991; 349: 569-571.

21 Kimberlin RH. Scrapie and possible relationship with viroids. Semin Virol 1990; 1: 153-162.

22 Aiken JM, Marsh RF. The search for scrapie agent nucleic acid. Microbiol Rev 1990; 54: $242-246$.

23 Bruce ME, Fraser H. Scrapie strain variation and its implications. Curr Top Microbiol Immunol 1991; 172: 125-138. 
24 Rohwer RG. The scrapie agent: 'a vinus by any other name'. Curr Top Microbiol Immunol 1991; 172: 195-232.

25 Büeler H, Aguzzi A, Sailer A, Greiner R-A, Autenried P, Aguet M. Mice devoid of PrP are resistant to scrapie. Cell 1993; 73: 1339-1347.

26 Prusiner SB. Scrapie prions. Annu Rev Microbiol 1989; 43: 345-374.

27 Oesch B, Westaway D, Walchli M et al. A cellular gene encodes scrapie PrP 27-30 protein. Cell 1985; 40: 735-746.

28 Chesebro B, Race R, Wehrly $\mathrm{K}$ et al. Identification of scrapie prion protein-specific messenger RNA in scrapie-infected and uninfected brain. Nature 1985; 315: 331-333.

29 Hope J, Morton LJ, Farquhar CF, Multhaup G, Beyreuther K, Kimberlin RH. The major polypeptide of scrapie-associated fibrils (SAF) has the same size, charge distribution and $\mathrm{N}$-terminal protein sequence as predicted for the normal brain protein (PrP). EMBO J 1986; 5: 2591-2597.

30 Basler K, Oesch B, Scott M et al. Scrapie and cellular PrP isoforms are encoded by the same chromosomal gene. Cell 1986; 46: 417-428.

31 Prusiner SB, DeArmond SJ. Prion diseases of the central nervous system. Monogr Pathol 1990; 32: 86-122.

32 Stahl N, Borchelt DR, Hsiao K, Prusiner SB. Scrapie prion protein contains a phosphatidylinositol glycolipid. Cell 1987; 51: 229-240.

33 Manson J, West JD, Thomson V, Mcbride P, Kaufman MH, Hope J. The prion protein gene a role in mouse embryogenesis? Development Camb 1992; 115: 117-122.

34 Bendheim PE, Brown HR, Rudelli RD et al. Nearly ubiquitous tissue distribution of the scrapie agent precursor protein. Neurology 1992; 42: 149-156.

35 Prusiner SB, Bolton DC, Groth DF, Bowman KA, Cochran SP, McKinley MP. Further purification and characterization of scrapie prions. Biochemistry 1982; 21: 6942-6950.

36 Prusiner SB, McKinley MP, Bowman KA et al. Scrapie prions aggregate to form amyloid-like birefringent rods. Cell 1983; 35: 349-358.

37 McKinley MP, Meyer RK, Kenaga L et al. Scrapie prion rod formation in vitro requires both detergent extraction and limited proteolysis. J Virol 1991; 65: 1340-1351.

38 Taraboulos A, Serban D, Prusiner SB. Scrapie prion proteins accumulate in the cytoplasm of persistently infected cultured cells. J Cell Biol 1990; 110: 2117-2132.

39 McKinley MP, Taraboulos A, Kenaga L et al. Ultrastructural localization of scrapie prion proteins in secondary lysosomes of infected cultured cells. J Cell Biol 1990; 111(5, Part 2): 316a.

40 Turk E, Teplow DB, Hood LE, Prusiner SB. Purification and properties of the cellular and scrapie hamster prion proteins. Eur J Biochem 1988; 176: 21-30.

41 Stahl N, Baldwin MA, Hecker R, Pan K-M, Burlingame, AL, Prusiner SB. Glycosylinositol phospholipid anchors of the scrapie and cellular prion proteins contain sialic acid. Biochemistry 1992; 31: 5043-5053.

42 Bolton DC, Rudelli RD, Currie JR, Bendheim PE. Copurification of Sp33-37 and scrapie agent from hamster brain prior to detectable histopathology and clinical disease. J Gen Virol 1991; 72: 2905-2913.

43 Oesch B, Groth DF, Prusiner SB, Weissmann C. Search for a scrapie-specific nucleic acid: a progress report. Ciba Found Symp 1988; 135: 209-223.

44 Kellings K, Meyer N, Mirenda C, Prusiner SB, Riesner D. Further analysis of nucleic acids in purified scrapie prion preparations by improved return refocusing gel electrophoresis. J Gen Virol 1992; 73: 1025-1029.

45 Prusiner SB, Scott M, Foster D et al. Transgenetic studies implicate interactions between homologous PrP isoforms in scrapie prion replication. Cell 1990; 63: 673-686.

46 Bolton DC, Bendheim PE. In: Bock G, Marsh J, eds. Novel infectious agents and the central nervous system. Chichester: John Wiley, 1988: 164-177.

47 Dickinson AG, Outram GW. Genetic aspects of unconventional virus infections: the basis of the virino hypothesis. Ciba Found Symp 1988; 135: 63-83.

48 Meyer N, Rosenbaum V, Schmidt B et al. Search for a putative scrapie genome in purified prion fractions reveals a paucity of nucleic acids. J Gen Virol 1991; 72: 37-49. 
49 Diringer $\mathrm{H}$. Transmissible spongiform encephalopathies (TSE) virus-induced amyloidoses of the central nervous system (CNS). Eur J Epidemiol 1991; 7: 562-566.

50 Bolton DC, McKinley MP, Prusiner SB. Identification of a protein that purifies with the scrapie prion. Science 1982; 218: 1309-1311.

51 Diringer H, Gelderblom H, Hilmert H, Ozel M, Edelbluth C, Kimberlin RH. Scrapie infectivity, fibrils and low molecular weight protein. Nature $1983 ; 306: 476-478$.

52 Gabizon R, McKinley MP, Groth D, Prusiner SB. Immunoaffinity purification and neutralization of scrapie prion infectivity. Proc Natl Acad Sci USA 1988; 85: 66176621.

53 Latarjet R, Muel B, Haig DA, Clarke MC, Alper T. Inactivation of the scrapie agent by near monochromatic ultraviolet light. Nature 1970; 227: 1341-1343.

54 Bellinger-Kawahara CG, Kempner E, Groth D, Gabizon R, Prusiner SB. Scrapie prion liposomes and rods exhibit target sizes of $55000 \mathrm{Da}$. Virology 1988; 164: 537-541.

55 Diedrich J, Wietgrefe $S$, Zupancic $M$ et al. The molecular pathogenesis of astrogliosis in scrapie and Alzheimer's disease. Microb Pathol 1987; 2/6: 435-442.

56 Sklaviadis T, Akowitz A, Manuelidis EE, Manuelidis L. Nuclease treatment results in high specific purification of Creutzfeldt-Jakob disease infectivity with a density characteristic of nucleic acid-protein complexes. Arch Virol 1990; 112, 215-228.

57 Dickinson AG, Meikle VM, Fraser H. Identification of a gene which controls the incubation period of some strains of scrapie agent in mice. J Comp Pathol 1968; 78: 293-299.

58 Bruce ME, Dickinson AG. Biological evidence that scrapie agent has an independent genome. J Gen Virol 1987; 68: 79-89.

59 Carlson GA, Kingsbury DT, Goodman PA et al. Linkage of prion protein and scrapie incubation time genes. Cell 1986; 46: 503-511.

60 Hunter N, Hope J, McConnell I, Dickinson AG. Linkage of the scrapie-associated fibril protein (PrP) gene and Sinc using congenic mice and restriction fragment length polymorphism analysis. J Gen Virol 1987; 68: 2711-2716.

61 Carlson GA, Goodman PA, Lovett M et al. Genetics and polymorphism of the mouse prion gene complex control of scrapie incubation time. Mol Cell Biol 1988; 8: 55285540.

62 Carlson GA, Westaway D, DeArmond SJ, Peterson Torchia M, Prusiner SB. Primary structure of prion protein may modify scrapie isolate properties. Proc Natl Acad Sci USA 1989; 86: 7475-7479.

63 Race RE, Graham K, Ernst D, Caughey B, Chesebro B. Analysis of linkage between scrapie incubation period and the prion protein gene in mice. J Gen Virol 1990; 71: 493-497.

64 Pattison IH. The relative susceptibility of sheep, goats and mice to two types of the goat scrapie agent. Res Vet Sci 1966; 7: 207-212.

65 Scott M, Foster D, Mirenda C et al. Transgenic mice expressing hamster prion protein produce species-specific scrapie infectivity and amyloid plaques. Cell 1989; 59: 847857.

66 Gajdusek DC. Unconventional viruses and the origin and disappearance of kuru. Science 1977; 197: 943-960.

67 Masters CL, Gajdusek DC, Gibbs CJ Jr. The familial occurrence of Creutzfeldt-Jakob disease and Alzheimer's disease. Brain 1981; 104: 535-558.

68 Hsiao K, Baker HF, Crow TJ et al. Linkage of a prion protein missense variant to Gerstmann-Sträussler syndrome. Nature 1989; 338: 342-345.

69 Baker HF, Ridley RM. The genetics and transmissibility of human spongiform encephalopathy. Neurodegeneration 1992; 1: 3-16.

70 Hsiao KK, Scott M, Foster D, Groth DF, DeArmond SJ, Prusiner SB. Spontaneous neurodegeneration in transgenic mice with mutant prion protein. Science 1990: 250: $1587-1590$.

71 Büeler $\mathrm{H}$, Fischer $M$, Lang $Y$ et al. Normal development and behaviour of mice lacking the neuronal cell-surface PrP protein (see comments). Nature 1992; 356: $577-582$. 
72 Hooper ML, Hardy K, Handyside A, Hunter S, Monk M. HPRT-deficient (Lesh-Nyhan) mouse embryos derived from germline colonization by cultured cells. Nature 1987; 326: 292-295.

73 Doetschman T, Maeda N, Smithies O. Targeted mutation of the Hprt gene in mouse embryonic stem cells. Proc Natl Acad Sci USA 1988; 85: 8583-8587.

74 Bradley A. In: Robertson EJ, ed. Teratocarcinomas and embryonic stem cells: a practical approach. Oxford: IRL Press, 1987: 113-151.

75 Capecchi MR. The new mouse genetics: altering the genome by gene targeting. Trends Genet 1989; 5: 70-76.

76 Brenner HR, Herczeg A, Oesch B. Normal development of nerve-muscle synapses in mice lacking the prion protein gene. Proc R Soc Lond B 1992; 250: 151-155.

77 Morris RGM. Development of a water-maze procedure for studying spatial learning in the rat. J Neurosci Meth 1984; 11: 47-60.

78 Lipp H-P, Van der Loos H. A computer-controlled Y-maze for testing vibrisso-tactile discrimination learning in mice. Behav Brain Res 1991; 45: 135-145.

79 Anisman H. In: Anisman H, Bignami G, eds. The psychopharmacology of aversively motivated behavior. New York: Plenum Press, 1978: 1-62.

80 McKinley MP, Bolton DC, Prusiner SB. A protease-resistant protein is a structural component of the scrapie prion. Cell 1983; 35: 57-62.

81 Prusiner SB, Groth D, Serban A, Stahl N, Gabizon R. Attempts to restore scrapie prion infectivity after exposure to protein denaturants. Proc Natl Acad Sci USA 1993; 90: 2793-2797.

82 Brown P, Liberski PP, Wolff A, Gajdusek DC. Conservation of infectivity in purified fibrillary extracts of scrapie-infected hamster brain after sequential enzymatic digestion or polyacrylamide gel electrophoresis. Proc Natl Acad Sci USA 1990; 87: 7240-7244.

83 Safar J, Wang W, Padgett MP et al. Molecular mass, biochemical composition, and physicochemical behavior of the infectious form of the scrapie precursor protein monomer. Proc Natl Acad Sci USA 1990; 87: 6373-6377.

84 Raeber A, Borchelt DR, Scott M, Prusiner SB. Attempts to convert the cellular prion protein into the scrapie prion isoform in cell-free systems. J Virol 1992; 66: 61556163.

85 Weissmann C. A 'unified theory' of prion propagation. Nature 1991; 352: 679-683.

86 Hecker R, Taraboulos A, Scott M, et al. Replication of distinct scrapie prion isolates is region specific in brains of transgenic mice and hamsters. Genes Dev 1992; 6: 1213-1228.

87 Manson J, Mcbride P, Hope J. Expression of the PrP gene in the brain of sinc congenic mice and its relationship to the development of scrapie. Neurodegeneration 1992; 1: 45-52.

88 Westaway D, Goodman PA, Mirenda CA, McKinley MP, Carlson GA, Prusiner SB. Distinct prion proteins in short and long scrapie incubation period mice. Cell 1987; 51: 651-662. 